\title{
Fibrous Histiocytoma of Anterior Ethmoidal Sinus: Case Report and Review of the Literature
}

\author{
Mohammad Sharifi Bahar Tafaghodi Yousefi \\ Eye Research Center, Mashhad University of Medical Science, Mashhad, Iran
}

\section{Keywords}

Fibrous histiocytoma $\cdot$ Ethmoid sinus

\begin{abstract}
Benign fibrous histiocytoma of the para nasal sinus is a rare tumor of this region which originates from mesenchymal cells. A 9-year-old girl presented with gradually enlarging mass above the medial canthus over 3 months. Orbital computerized tomography scan showed a round well-differentiated homogeneous mass in the anterior ethmoidal sinus. Histology and immunohistochemistry analysis after excision revealed proliferation of spindle-shaped fibroblasts in storiform pattern and histiocytes without mitosis and anaplasia. After 9 months from surgical excision, recurrence occurred which resulted in total excision again. This is the first reported case of benign fibrous histiocytoma involving the ethmoid sinus in Iranian people. Rare sinus tumor should be considered in the differential diagnosis of sinus tumors.
\end{abstract}

\section{Introduction}

Benign fibrous histiocytoma $(\mathrm{BFH})$ is an uncommon tumor of the nasal and sinus cavity which originates from mesenchymal cells [1]. Cutaneous BFH usually originates in sun-exposed skin and noncutaneous in subcutaneous tissues of extremities and rarely visceral space [2]. The benign deep soft tissue variant seems to be more prevalent in children [3]. We reported a 9-year-old girl with a rare ethmoidal tumor who experienced 1 episode of recurrence. Local recurrence is a characteristic of $\mathrm{BFH}$, so this probability should be considered [4]. 
Fig. 1. Coronal orbital CT scan shows a well-defined homogeneous mass with no bone erosion in the anterior ethmoidal sinus.

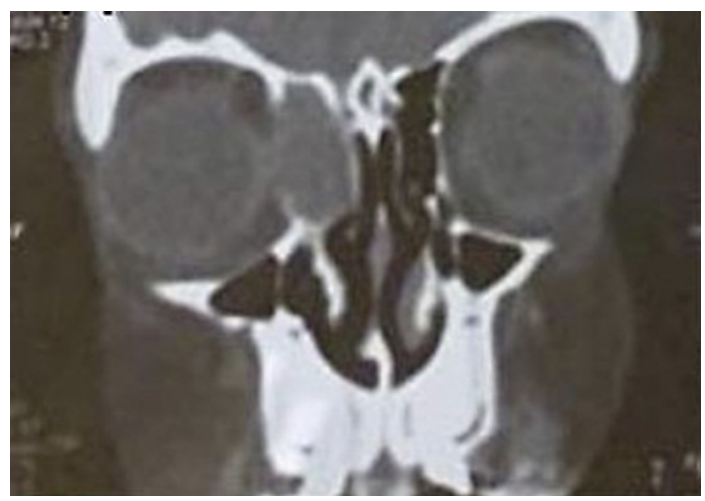

Fig. 2. Axial orbital CT scan of the patient.

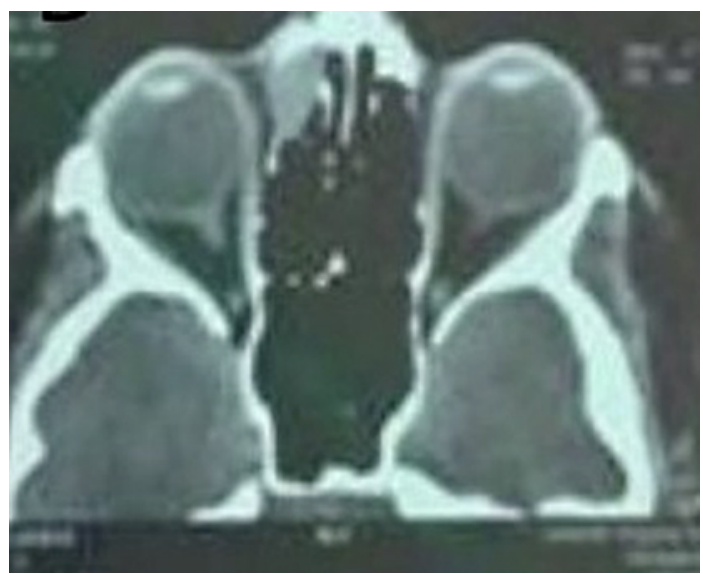

\section{Case Report}

A 9-year-old girl was referred for a right medial canthal mass to our eye hospital. Ocular examination showed normal visual acuity, normal pupillary reflex, no proptosis, and no movement limitation except a firm, fixed painless mass located in the medial canthus superior to the medial canthal tendon. Biomicroscopic and funduscopic examinations were unremarkable. She reported a gradually enlarging mass over 3 months. No other symptoms such as headache or nasal symptoms were noted. Orbital CT scan revealed a round welldefined homogeneous mass without bony erosion in the anterior ethmoidal sinus (Fig. 1, 2). Due to a large and anterior position of the mass in the anterior sinus, endoscopic approach was not recommended by a rhinologist, so surgery was performed via frontoethmoidal incision on the right lateral wall of the nose. A yellowish lobulated mass was totally excised (Fig. 3).

Biopsy shows proliferation of spindle-shaped fibroblasts in storiform pattern, infiltration of inflammatory lymphoblasts and neutrophils with epithelioid and multinucleated giant cell granuloma reaction, and histiocytes accompanied by necrosis and fibrosis foci suggestive of BFH (Fig. 4). Immunohistochemistry revealed positive vimentin and negative results for desmin. Immunostaining was negative for CD34 and positive for CD68. After 9 months, she came with recurrence of the tumor with same clinical and pathologic finding as the primary tumor. 


\section{Case Reports in Oncology}

\begin{tabular}{l|l}
\hline Case Rep Oncol 2021;14:1304-1309 \\
\hline DOI: 10.1159/000518682 & $\begin{array}{l}\text { @ 2021 The Author(s). Published by S. Karger AG, Basel } \\
\text { www.karger.com/cro }\end{array}$ \\
\hline
\end{tabular}

Sharifi and Tafaghodi Yousefi: Fibrous Histiocytoma of Sinus

Fig. 3. Yellowish multiobulated excised tumor.
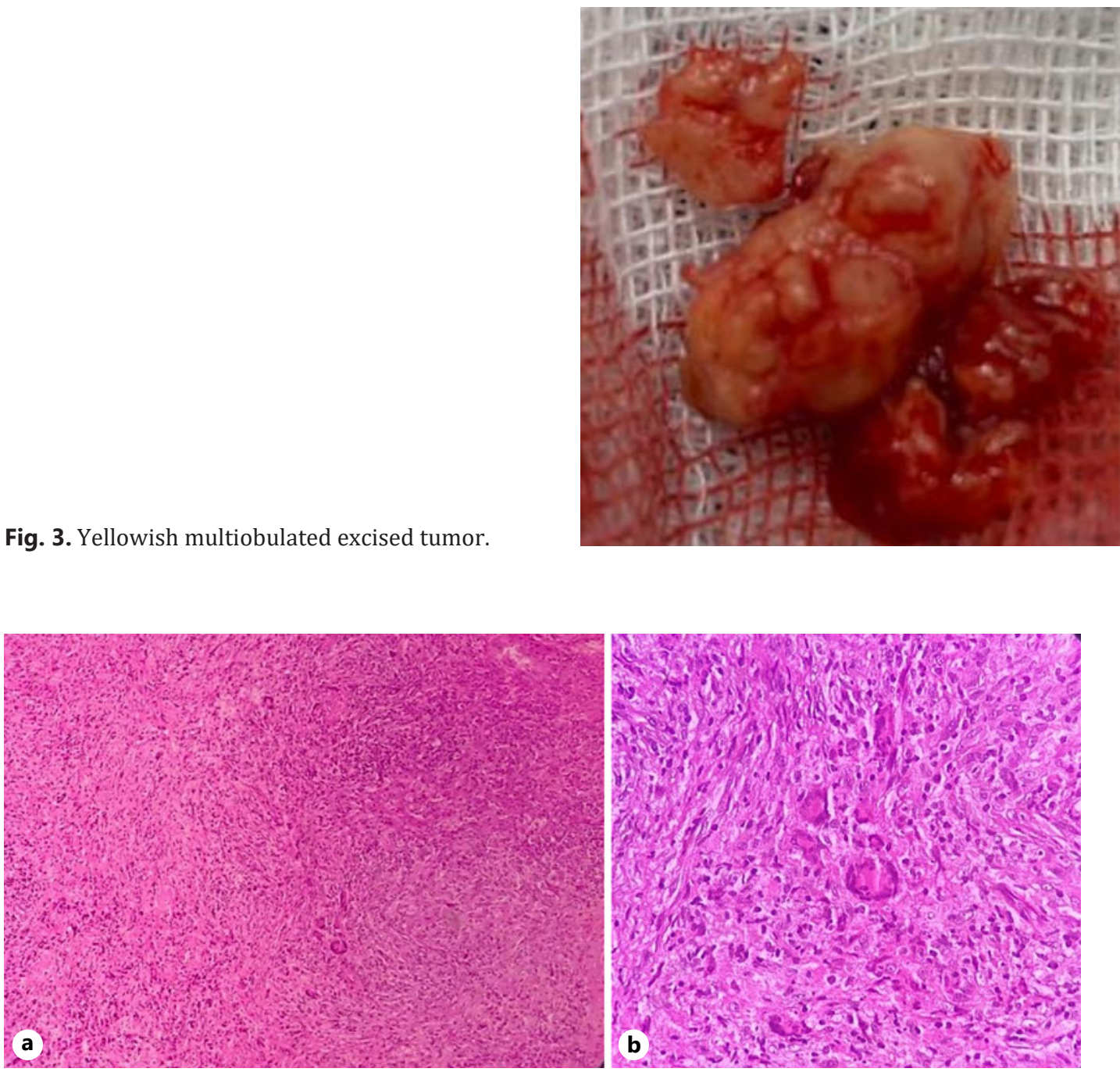

Fig. 4. Histopathology shows proliferation of spindle-shaped fibroblasts in storiform and fascicular pattern and infiltration of inflammatory lymphoblasts and neutrophils with epithelioid and multinucleated giant cell granuloma reaction (H\&E stain, A10).

\section{Discussion}

Fibrous histiocytoma (FH) could be found in the whole body especially in the skin, deep soft tissue, and bone [5, 6]. The head and neck are involved infrequently. In 1978, Weiss and Enzinge [2] reported 200 cases of malignant FH and only 6 occurred in the head and neck area [4]. FH of the head and neck usually occurs in the sun-exposed region, and involvement of the nasal cavity and paranasal sinus is seen infrequently [5-7]. The exact origin site of FH in the nasal cavity and/or paranasal sinuses cannot be determined. It might arise in the bone or in the connective tissue supporting these structures [8]. Clinical findings of FH in nasal and sinus cavities are similar to other soft tissue masses in these regions. Depending on the location, it may produce nasal obstruction, facial swelling and deformity, teeth loosening, epistaxis, pain, periorbital mass, and proptosis. Imaging may show sinus opacification or cloudiness, a mass, or bone destruction [8]. CT scan and MRI can help to diagnose local invasions and metastasis [8]. 
Histological diagnosis was based on presence and pattern of certain distinct findings: fibrocytes or fibroblast cells with elongated spindle-shaped nuclei arranged in cartwheel, pin-wheel, storiform, or spiral nebular patterns accompanied by round histiocytes. Depending on the proportion of these 2 elements, tumor morphologies are variable. In most FH, both patterns are usually found, but in a few cases, only 1 element can be identified [8].

Previous studies showed FH tumors contained 2 cell types, histiocytic and fibroblastic and also cells with both differentiation in separate part of the same cell and undifferentiated mesenchymal cells [9]. These studies suggest that FH might be derived from undifferentiated mesenchymal stem cells that can differentiate into 2 pathways, one fibroblastic and the other histiocytic [9].

The cell differentiation and anaplasia are concerned but not diagnostic in tumor behavior. The fibroblast-like and histiocyte-like elements may appear cytologically benign with mature-appearing cells containing small bland nuclei and no mitoses. At the other end of the spectrum, the tumor may exhibit cellular anaplasia and numerous mitoses [8].

Histological classification of FH to benign and malignant is complicated. Some lesions with numerous mitoses and atypical cells are local and rarely metastasized [5-7]. On the other hand, occasionally, FH without anaplasia and mitosis has metastasized [7, 10]. But, lesions that demonstrated cellular anaplasia and numerous mitoses showed a more invasive behavior requiring wide local excision or even radical resection [11].

Immunohistochemical and electron microscopic studies are nonspecific and provide confirmatory evidence of FH by excluding other diagnoses [12]. Tumor cells are usually positive for vimentin and negative for lysozyme, desmin, S 100, keratin, and factor XIIIa [13]. No specific marker was detected for $\mathrm{BFH}$, and therefore diagnosis was made by exclusion of other lesions.

Immunostaining for CD68 can be found in any tumor-containing lysosomal granules or phagolysosomes as in our case [12]. Factor XIIIa has occasionally been reported for BFH [14]. Since local invasion and recurrence are characteristics of an FH lesion, wide local excision is the treatment of choice [14].

To our knowledge, few cases of BFH of the ethmoidal sinus have been reported. Nair et al. [11] reported an infant with proptosis and a $1.93 \times 2.18 \mathrm{~cm}$ cystic lesion within the left ethmoid which was removed by endoscopy. After 3 months, recurrence happened in their case, and surgical excision was performed. Kau et al. [15] presented a 76-year-old patient with BFH of the frontoethmoidal sinus associated with orbital abscess. Our case presented with medial canthal mass without nasal symptom. She had recurrence of tumor as occurred in previous case reports.

\section{Conclusion}

FH of the ethmoidal sinus is a rare tumor of head and neck regions. It may present with only a mass lesion without accompanying nasal and/or ocular symptoms. Complete excision and pathologic evaluation are necessary. Recurrence is likely. This is the first report of FH of paranasal sinus in an Iranian girl.

\section{Acknowledgments}

The authors thank all their colleagues in their eye research center for their cooperation.

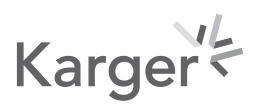




\section{Case Reports in Oncology}

Case Rep Oncol 2021;14:1304-1309

\begin{tabular}{l|l}
\hline DOI: $10.1159 / 000518682$ & ( 2021 The Author(s). Published by S. Karger AG, Basel
\end{tabular} www.karger.com/cro

Sharifi and Tafaghodi Yousefi: Fibrous Histiocytoma of Sinus

\section{Statement of Ethics}

This manuscript was approved by the Ethics Committee of Mash had University of Medical Sciences (Reference No. 93418). Written informed consent for publication was obtained from the patient's parents for publication of this case report and any accompanying images.

\section{Conflict of Interest Statement}

The authors have no conflicts of interest to declare.

\section{Funding Sources}

This research did not receive any funding.

\section{Author Contributions}

Data collection, writing, and submission of this manuscript were done by Dr. Sharifi and Dr. Tafaghodi.

\section{Data Availability Statement}

All data in this study can be reached by contacting the corresponding author.

\section{References}

1 Chen TC, Kuo T, Chan HL. Dermatofibroma is a clonal proliferative disease. J Cutan Pathol. 2000;27(2):36-9.

2 Weiss SW, EnzingerM FM. Malignant fibrous histiocytoma: an analysis of 200 cases. Cancer. 1978;41(4):225066.

3 Fletcher CDM. World Health Organization classification of tumors: pathology and genetics of tumors of soft tissue and bone. Lyon: IARC Press; 2013. p. 104.

4 Yamada H, Ishii H, Kondoh T, Seto K. A case of benign fibrous histiocytoma of the upper lip in a 6-month-old infant. J Oral Maxillofac Surg. 2002;60(3):451-4.

5 Fretzin DF, Helwig EB. Atypical fibroxanthoma of the skin. A clinicopathologic study of 140 cases. Cancer. 1973;31(4):1541-52.

6 Kempson RL, McGavran MH. Atypical fibroxanthoma of the skin. Cancer. 1964;1793(3):1463-71.

7 Kempson RL, Kyriakos M. Fibroxanthosarcoma of the soft tissues. A type of malignant fibrous histiocytoma. Cancer. 1972;29(2):961-76.

8 Perzin KH, Fu YS. Non-epithelial tumors of the nasal cavity, paranasal sinuses and nasopharynx: a clinicopathologic study XI. fibrous histiocytomas. Cancer. 1980;45(10):2616-26.

9 Fu YS, Gabbiani G, Kaye GI, Lattes R. Malignant soft tissue tumors of probable histiocytic origin (malignant fibrous histiocytomas), general considerations and electron microscopic and tissue culture studies. Cancer. 1975;35(6):176-98.

10 Rosas-Uribe A, Ring AM, Rappaport H. Metastasizing retroperitoneal fibroxanthoma (malignant fibroxanthoma). Cancer. 1970;26(4):827-31.

11 Nair S, Ramalingam WV, Bharadwaj R, Ramesh AV, Malik A, Mohan S. Benign fibrous histiocytoma of the ethmoids in an infant. Med J Armed Forces India. 2015;71(2):S217-20.

12 Femiano F, Scully C, Laino G, Battista G. Benign fibrous histiocytoma (BHF) of the cheek: CD 68-KP1 positivity. Oral Oncol. 2001;37(8):673-5.

13 Calonje E, Mentzel T, Fletcher CD. Cellular benign fibrous histiocytoma. Clinicopathologic analysis of 74 cases of a distinctive variant of cutaneous fibrous histiocytoma with frequent recurrence. Am J Surg Pathol. 1994 Jul;18(7):668-76.

\section{Karger's}




\section{Case Reports in Oncology}

Sharifi and Tafaghodi Yousefi: Fibrous Histiocytoma of Sinus

14 Mafee MF. Nonepithelial tumors of the paranasal sinuses and nasal cavity. Role of CT and MR imaging. Radiol Clin North Am. 1993;31(1):75-90.

15 Kau HC, Yang CF, Liu IT, Kao SC, Hsu WM, Teng MM, et al. Benign fibrous histiocytoma associated with a frontoethmoidal mucopyocele and orbital abscess. Ophthalmic Plast Reconstr Surg. 2007;23(3):236-8. 